Published in final edited form as:

Blood Rev. 2016 March ; 30(2): 111-118. doi:10.1016/j.blre.2015.08.005.

\title{
The role of blood rheology in sickle cell disease
}

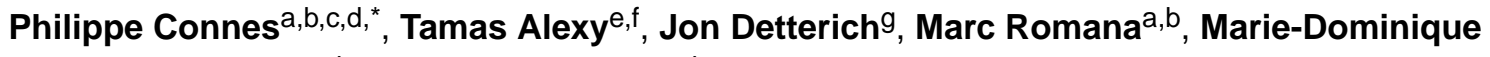 \\ Hardy-Dessources ${ }^{a, b}$, and Samir K. Ballas ${ }^{h}$ \\ aInserm UMR 1134, Hôpital Ricou, CHU de Pointe-à-Pitre, 97157 Pointe-à-Pitre, Guadeloupe \\ bLaboratory of Excellence GR-Ex «The red cell: from genesis to death», PRES Sorbonne Paris \\ Cité, 75015 Paris, France \\ CInstitut Universitaire de France, Paris, France \\ 'Laboratoire CRIS EA647, Section "Vascular Biology and Red Blood Cell”, Université Claude \\ Bernard Lyon 1, 69100 Villeurbanne, France \\ eDivision of Cardiology, Emory University School of Medicine, Atlanta, GA, USA \\ fSection of Cardiology, Atlanta VA Medical Center, Decatur, GA, USA \\ 'Children's Hospital Los Angeles, Division of Cardiology, USA \\ hDepartment of Medicine, Cardeza Foundation for Hematologic Research, Jefferson Medical \\ College, Thomas Jefferson University, Philadelphia, PA, USA
}

\begin{abstract}
Studies performed in the last decades have highlighted the need to better understand the contribution of the endothelium, vascular function, oxidative stress, inflammation, coagulation, hemolysis and vascular adhesion mechanisms to the pathophysiology of acute vaso-occlusive like events and chronic organ damages in sickle cell disease (SCD). Although SCD is a hemorheological disease, a few works focused on the contribution of blood viscosity, plasma viscosity, red blood cell deformability and aggregation in the pathophysiology of SCD. After a brief description of basic hemorheology, the present review focuses on the role of the hemorheological abnormalities in the causation of several SCD complications, mainly in sickle cell anemia and hemoglobin (Hb) SC disease. Several genetic and cellular modulators of blood rheology in SCD are discussed, as well as unresolved questions and perspectives.
\end{abstract}

\section{Keywords}

Sickle cell disease; Blood viscosity; Red blood cell deformability; Red blood cell aggregation; Vaso-occlusive crises

"Corresponding author at: Laboratoire CRIS EA647, Section "Vascular Biology and Red Blood Cell”, Université Claude Bernard Lyon 1, 69100 Villeurbanne, France. pconnes@yahoo.fr (P. Connes).

Conflict of interest statement

None. 


\section{Introduction}

Sickle cell disease (SCD) is the most frequent genetic disease in the world, with sickle cell anemia (SCA; i.e. homozygous sickle cell disease or HbSS), and to a lesser extent hemoglobin SC disease (SC), reaching the highest prevalence [1]. It is estimated that over 300,000 children are born each year with a severe inherited hemoglobinopathy, over $80 \%$ of these in low-or middle-income countries, and approximately 220,000 newborns are affected by SCA [1].

SCA is characterized by a single nucleotide mutation (adenine-thymine) in exon I of the beta globin gene that leads to the presence of sickle hemoglobin (HbS) resulting from the substitution of valine for glutamic acid at the sixth position of the $\beta$-globin chain. The hydrophobic residue of valine associates with other hydrophobic residues causing $\mathrm{HbS}$ molecules to aggregate, forming fibrous precipitates when hemoglobin is deoxygenated. This phenomenon is called "HbS polymerization" and is responsible for the characteristic shape change termed "sickling" of red blood cells (RBCs). Sickle RBCs are rigid and do not easily flow through the microcirculation, causing frequent vaso-occlusive episodes in affected patients. Recurrent $\mathrm{HbS}$ polymerization leads to numerous RBC and systemic physiological abnormalities with variable phenotypic severity [2].

Hemoglobin $\mathrm{C}(\mathrm{HbC})$ is a variant in which lysine is substituted for glutamic acid at position 6 of the $\beta$-globin chain. $\mathrm{HbC}$ has a tendency to crystallize in oxy-configuration [3]. When $\mathrm{HbC}$ and $\mathrm{HbS}$ are present together (HbSC disease), this may lead to an acceleration of $\mathrm{HbC}$ crystallization [4], which promotes RBC dehydration. As a consequence, mean corpuscular $\mathrm{Hb}$ concentration (MCHC) increases, inducing $\mathrm{HbS}$ polymerization, and reducing $\mathrm{RBC}$ deformability [5,6]. Thereby, as well as RBCs from SCA patients, RBCs from SC patients are also characterized by a loss of deformability. SC patients are marked by milder anemia than SCA patients with an over-representation of chronic organ complications such as retinopathy, otologic disorders or osteonecrosis [7].

At its core, SCD is a hemorheological disease [8], with $\mathrm{HbS}$ polymerization leading to the loss of RBC deformability considered to be the primary factor responsible for the vasoocclusive crises (VOC) and all downstream progressive organ dysfunctions. While the underlying genetic mutations described above are well known, the exact pathophysiological mechanisms responsible for the individual phenotypic manifestations and long term complications are not yet fully elucidated. After a brief description of basic hemorheology, the present review focuses on the role of the hemorheological abnormalities in the occurrence of several SCD complications.

\section{Basic hemorheology}

Hemorheology focuses on blood flow as well as the properties and interaction of blood cells. The specific flow behavior of blood is mainly determined by its structure. Blood is a twophase liquid and its rheological properties are determined by the flow properties of both phases and the relative contribution of these phases to the total volume of blood. The two phases are 1) plasma and 2) cellular components. 


\subsection{Blood viscosity}

Blood viscosity is an important determinant of local flow characteristics. Blood exhibits shear thinning behavior: its viscosity decreases exponentially with increasing shear rates. Therefore, no single viscosity value exists to characterize blood viscosity, it should rather be expressed as a function of shear rate, which mainly depends on the blood flow rate and the vessel radius (Fig. 1) [9]. In addition, blood has visco-elastic and thixotropic properties also affecting local hemodynamics. A thixotropic fluid is a fluid whose viscosity is a function not only of the shearing condition, but also of the previous history of motion within the fluid [10]. Indeed, for a given flow/shear rate, blood viscosity usually decreases with the length of time the fluid has been in motion (Fig. 2). The relative contribution of RBCs (the most significant cellular element) is represented by the hematocrit (Hct) value. A rise in Hct increases blood viscosity at all shear rates and thixotropy, more particularly at low shear rate, like in veins and venules $[9,10]$.

Plasma is a Newtonian fluid, with its viscosity being independent of shear rate and dependent mainly on the concentration of fibrinogen. Increased plasma viscosity affects blood viscosity and is also an important modulator of endothelial nitric oxide synthase activity through its effects on wall shear stress [11].

\subsection{RBC deformability and aggregation in normal blood}

The shear thinning characteristics of blood are determined primarily by the mechanical properties of circulating erythrocytes. There are two unique RBC characteristics that are primarily responsible for this non-Newtonian behavior. At high shear rates (characterized by high shear forces), RBCs undergo an extensive passive shape change (RBC deformability) forcing them to align parallel with laminar flow streamlines [9]. As a consequence, blood viscosity and the internal resistance of blood to flow decrease [9]. RBC deformability is determined by cell geometry, cytoplasmic composition, internal viscosity and membrane characteristics [12]. At low flow rates and under low shear forces, normal RBCs have a biconcave disk shape and they lose their parallel orientation with the flow streamlines [9].

In addition, $\mathrm{RBCs}$ tend to form aggregates at low shear rates (i.e., in veins) contributing to the observed exponential increase in blood viscosity. $\mathrm{RBC}$ aggregation is a physiological process under low shear conditions or stasis and is characterized by the formation of threedimensional structures called "Rouleaux" similar to a stack of coins. This unique process requires low energy and is reversible: $\mathrm{RBC}$ aggregates may disaggregate, at least partly, in vascular regions where shear rate is high, such as in arteries, arterioles or capillaries [13]. RBC aggregation depends on the presence of macromolecules in the suspending medium with molecular weight above a well-defined cutoff [14]. Fibrinogen is the most physiologically relevant macromolecule to promote RBC aggregation in the blood. In addition, RBC surface properties, including surface charge and glycocalyx depth, also play an important role in this process [14]. 


\section{Hemorheological profile in SCD at steady state}

Owing to the chronic severe anemia, patients with SCA have lower blood viscosity at native Hct under oxygenated conditions than individuals with normal hemoglobin [15]. As a consequence, there is a decrease in the Hct/blood viscosity ratio reflecting RBC oxygen transport effectiveness [15-17], a parameter that correlates well with the level of tissue oxygenation in combined SCA and SC patients [18]. However, when adjusted to a normal Hct levels (40-45\%), SCA patients have blood viscosity that is above the controls under oxygenated conditions (Fig. 3) due to the presence of irreversibly sickled cells (ISCs). When de-oxygenated, the sickling of RBCs causes a further rise in blood viscosity at all shear rates [8]. Plasma viscosity has also been shown to be slightly increased in SCA patients at steady state [19] likely due to the increased concentration of circulating fibrinogen and other acute phase reactant proteins.

In contrast to SCA individuals, patients with HbSC disease have higher blood viscosity than healthy controls at native Hct [15] as the milder anemia in these patients is unable to fully offset the rheological effects of abnormal RBCs. Both SC and SCA patients have decreased $\mathrm{RBC}$ deformability in comparison to healthy individuals but the situation is worse for SCA patients [15]. RBC aggregation properties have been poorly studied in SCD but several studies reported that $\mathrm{RBC}$ aggregation (which depends on the number of RBC aggregates and time for RBC aggregates formation) is rather decreased in both SCA and SC patients compared to healthy individuals. In contrast, once formed, sickle RBC aggregates are 2 to 3 folds more robust than healthy RBC aggregates [15,20]. The lower RBC aggregation seems to be due to the low ability of the rigid ISCs to form aggregates [8,21]. Deoxygenating sickle cell blood in vitro results in a further decrease of RBC deformability and RBC aggregation [22].

\section{Hemorheological profile in SCD during vaso-occlusive crisis (VOC)}

Very few studies have investigated the hemorheological changes during acute VOC but it seems clear that overall RBC deformability decreases due to massive sickling and RBC dehydration [23,24]. Rieber et al. [25] described a uniform pattern in RBC rheology during the evolution of VOC in 8 SCA patients. Comparison of data on the first and last day of hospitalization showed decreased percentage of circulating sickled cells associated with increased overall $\mathrm{RBC}$ filterability upon recovery. The phenomenon is likely related to the lysis of the most rigid and fragile sickled cells and probably, to a lesser extent, to the blockade of the most rigid RBCs into the microcirculation. Unfortunately, however, no data is available at steady state in these patients. Kenny et al. [26] showed that RBC deformability was significantly reduced on day 1 of crisis in nine SCA patients and $24 \mathrm{~h}$ before the onset of pain in one additional patient. RBC deformability gradually returned to pre-crisis values by day 8 to 9 . Ballas and Smith [24] expanded these observations by conducting prospective studies on 36 SCA patients over five years and found that RBC deformability was reduced early in the crisis and increased to values higher than the steady state as the crisis resolved. Given that RBC deformability varies inversely with the number of irreversible sickle cells and dense cells [27,28], the uniform description of changes in $\mathrm{RBC}$ deformability during the evolution of the vaso-occlusive crisis by these different 
groups supports the reciprocal changes in the percentage of dense cells as the vaso-occlusive event evolves. Available data to date suggests the following RBC changes during the evolution of a VOC: [1] extensive hemolysis in some, but not all, patients; [2] the overall percentage of sickled cells (including reversibly and irreversibly sickled cells) increases one to three days prior to the clinical crisis followed by a decrease as patients recover; [3] consequently, bulk RBC deformability decreases early in the crisis and increases later as the percentage of rigid cells decreases [24,26-28].

No study to date measured the changes in RBC aggregation during a vaso-occlusive event in SCA and only limited data is available on erythrocyte sedimentation rate (ESR), a parameter that is affected by both Hct and RBC aggregation [29,30]. The increase of fibrinogen during VOC could promote RBC aggregation [30] but further studies are needed to directly investigate this parameter during crisis.

Several studies reported an increase in apparent plasma viscosity during VOC with peak values on or after day $6[29,31,32]$. The observation also suggests that the increase, at least in part, is secondary to the increase in plasma fibrinogen.

Each of the hemorheological abnormality previously described may increase blood viscosity at low and/or high shear rates, further altering blood flow.

\section{Hemorheological predictors of SCD complications}

One of the most challenging tasks in the field of SCD is the prediction and prevention of acute and chronic disease complications with the aim to improve the clinical management of affected patients. Several bio-markers and physiological parameters have been evaluated in this regard and the work is still underway. Recently, a new model of SCA pathophysiology has been proposed [33,34] with the presence of two clinical/biological phenotypes: 1) the hemolytic-endothelial dysfunction phenotype and 2) the viscosity-vaso-occlusion phenotype. These two sub-phenotypes overlap and are not completely distinct [34].

\subsection{Hemolytic-endothelial dysfunction phenotype}

The hemolytic-endothelial dysfunction phenotype in SCA is characterized by a high rate of hemolysis that not only impacts vascular physiology at the pre-capillary arteriole level, but also in large arteries [34, 35]. As a result of hemolysis, free hemoglobin is released into plasma. Part of the free hemoglobin quickly reacts with haptoglobin and the complex is cleared from plasma. However, this system is insufficient to eliminate the excess of free circulating hemoglobin in SCA and a large amount reacts with nitric oxide (NO) to produce methemoglobin and nitrate ultimately leading to reduced NO bioavailability [34]. The release of RBC arginase into the plasma catabolizes plasma arginine reducing its bioavailability. In addition, heme and heme-iron dissociate from $\mathrm{Hb}$ catalyzing the production of reactive oxygen species (ROS) that serve as potent NO scavengers [34]. The increased oxidative stress stimulates RBC senescence, RBC phagocytosis by macrophages and extravascular hemolysis. Oxidization of the flippase enzyme and/or activation of the phospholipid transporter scramblase lead to the disruption of membrane phospholipid asymmetry followed by phosphatylserine exposure on the outer membrane leaflet and 
membrane vesiculation resulting in a release of $\mathrm{RBC}$ microparticles. $\mathrm{RBC}$ microparticles have been recently demonstrated to cause vaso-occlusion at the kidney level in a murine model of SCD [36] and to scavenge NO, hence reducing its bioavailability [37]. The decline in blood NO content leads to endothelial dysfunction, over-expression of vascular adhesion molecules and impaired vasomotor tone [38,39]. In support of these mechanisms, plasma from patients with SCA contains cell-free ferrous oxyhemoglobin, which stoichiometrically consumes micromolar quantities of $\mathrm{NO}$ and abrogates forearm blood flow response to NO donor infusion [40]. Although not shared by all the scientific community [41], these biological alterations seem to be involved in the development of pulmonary hypertension [42], glomerulopathy [43], leg ulcers [44], priapism [34], cerebral vasculopathy [35], ischemic stroke [45] and clinically silent cerebral infarction [46]. In SCA patients with glomerulopathy, Lamarre et al. [47] reported lower Hb level and RBC deformability as well as higher RBC aggregates strength when compared to subjects with normal kidney function. Decreased RBC deformability and elevated RBC aggregates strength may disturb blood flow at the pre-capillary level, thereby promoting impaired oxygen delivery, tissue damage and end organ dysfunction. Connes et al. [48] also reported decreased RBC deformability and lower Hct/blood viscosity ratio in SCA patients with recurrent leg ulcers compared to those who never had this complication. Decreased RBC deformability seems to be the hallmark of the hemolytic phenotype with the more rigid RBCs being more fragile [21]. The findings of Bartollucci et al. [49] are in agreement with this hypothesis as they reported higher number of dense RBCs in patients with leg ulcers, renal dysfunction and priapism. It is unknown whether patients with pulmonary hypertension and cerebral vasculopathy are also characterized by the presence of increased number of rigid RBCs but it has been recently [35] suggested that this might indeed be the case. Further studies are needed to explore this hypothesis.

\subsection{Viscosity-vaso-occlusion phenotype}

Painful vaso-occlusion, acute chest syndrome and osteonecrosis have been considered in the viscosity-vaso-occlusion phenotype with vascular occlusion beginning primarily in the postcapillary venules [34]. A large epidemiological study in the United States (the Cooperative Study of Sickle Cell Disease) demonstrated that high Hct and $\mathrm{Hb}$ increased the risks for VOC [50] and acute chest syndrome [51], respectively, in SCA. This is in agreement with previous findings showing that $\mathrm{Hb}$ value is an independent predictor for the development of acute pain crisis in SCA [52]. As discussed before, Hct is a key determinant of blood viscosity, particularly at low shear where the rise in viscosity is exponential. Two recent works further strengthened this observation: one performed in SCA adults [53] and the other one in children [54]. These studies found that SCA patients with more frequent hospital admissions for VOC had higher blood viscosity at steady state than patients with less frequent hospitalizations. Moreover, blood viscosity was shown to rise further during a vasoocclusive episode [30].

SC patients generally have higher blood viscosity than SCA subjects at native Hct [15]. Despite this observation, SC patients are at lower risk for developing VOC. One possible explanation is that overall vascular function and vasoreactivity would be better preserved in SC than in SCA patients [55,56], owing to the reduced amount of circulating toxic plasma 
free $\mathrm{Hb}$ and heme-derived products. Nevertheless, elevated blood viscosity in SC patients seems to predispose this population to proliferative retinopathy [57] and certain otologic disorders [58].

The pathogenesis of osteonecrosis in SCA subjects is not yet entirely clear [59]. The proximal epiphyseal segments of the humerus and the femur are in tightly enclosed spaces with a single feeding artery and draining vein. One possible scenario is that increased blood viscosity limits venous outflow leading to an increase in tissue pressure within the enclosed space [59]. This pressure then could reduce arterial input with resultant hypoxia of the marrow and bone. While abnormal blood viscosity is definitely involved in the pathophysiology of acute painful VOC in SCA, its role is less clear in the development of osteonecrosis $[60,61]$. This paradox is due to the fact that patients with osteonecrosis have increased RBC deformability, which compensates for the increased Hct and leads to a relative "normalization" of blood viscosity in SCA patients [60]. This hemorheological picture seems to be specific of SCA patients with osteonecrosis since SC patients with and without this complication are not different regarding blood rheology or hematology [58].

Although an increase of RBC deformability is beneficial for blood flow and tissue perfusion in the healthy population, increased RBC deformability in SCA patients seems to increase the risks for osteonecrosis [60] and acute painful vaso-occlusion [52,54]. While RBC deformability is decreased during vaso-occlusive events, Ballas et al. [24] demonstrated that high level of RBC deformability during the recovery phase of a painful vaso-occlusive event was a predictor of a new painful crisis. Lande et al. [52] also reported a significant and positive correlation between the incidence of painful crisis in SCA and RBC deformability, a result initially reported by Ballas et al. [62,63] This surprising finding may be explained by the fact that sickle RBCs with the highest deformability are also the most adherent RBCs to the vascular wall, thus decreasing the lumen of microvessels, slowing blood flow and initiating vascular occlusion [63-65]. While increased or decreased RBC deformability is not a predictor of the occurrence of VOC or osteonecrosis in SC patients, reduced RBC deformability seems to increase the risks for retinopathy in this population [58].

\section{Modulators of blood rheology in SCD}

Evidence accumulates that two overlapping phenotypes of SCD exists: 1) patients prone to hemolytic complications as indicated by decreased Hct, low blood viscosity, decreased RBC deformability and $\mathrm{RBC}$ aggregation abnormalities; 2) patients prone to vaso-occlusive events as marked by increased Hct, increased RBC deformability (but with values below the normal controls) and increased blood viscosity. A few molecular and cellular modulators have been identified to possibly explain these phenotypic differences.

\section{1. $a$-Gene deletions/a-thalassemia}

About 30-40\% of SCD patients have coincidental a-gene deletions [66]. The presence of athalassemia has been shown to modulate the clinical presentation of SCA [34]. Several studies reported a protective effect of a-thalassemia in SCA for the following complications: glomerulopathy [43,47,67], cerebral vasculopathy/ischemic stroke [35,45,68], leg ulcers $[69,70]$, and priapism [71]. The reduced proportion of $\mathrm{HbS}$, lower mean corpuscular 
hemoglobin concentration and decreased hemolysis are likely to provide the protection against the above complications [72,73]. The reduced rate of hemolysis in SCA patients with at least one a-gene deleted could lead to improved NO bio-availability and bio-activity, hence better conserved vascular function although this hypothesis has never been tested [34]. Complementary to the above papers, the recent study of Lamarre et al. [47] found that athalassemia may protect from vascular complications, specifically from glomerulopathy, through its effect on RBC rheology. The authors demonstrated that the presence of athalassemia in SCA patients improved RBC deformability, a finding also reported previously by others [63,72], and decreased the strength of RBC aggregates. These RBC rheological effects may mechanically improve blood flow and tissue perfusion while limiting hemolysis at the same time. On the other hand, co-existence of a-thalassemia and SCA has been shown to increase the incidence of painful VOC and the risk of osteonecrosis $[50,60,61,74]$. The greater RBC deformability observed in SCA patients with a-thalassemia could predispose them to develop VOC and osteonecrosis because more deformable sickle RBCs are more adherent to the vascular wall than dense rigid RBCs, hence initiating vaso-occlusion [6365]. In contrast to SCA patients, the presence of a-thalassemia in sickle SC disease seems to protect patients from developing osteonecrosis or vaso-occlusive events [34,66]. Further studies are warranted to understand the reasons of this protection.

\section{2. $\beta$-globin haplotypes}

The HbS gene may be found on a genetic background of four to five major $\beta$-globin-like gene cluster haplotypes [75]. Very few studies investigated the effects of $\beta$-globin haplotypes on hematological and hemorheological parameters in SCA but Powars et al. [76] reported lower RBC deformability in patients with the CAR/BEN haplotypes, known to be one of the haplotype configuration associated with a severe expression of the disease. This was mainly due to a low HbF level. Further studies are needed to test the effects of $\beta$-globin haplotypes on the other hemorheological parameters, as well as the effects of $\beta$-globin haplotypes combined or not with a-thalassemia.

\subsection{HbF level}

The large Cooperative Study on Sickle Cell Disease previously demonstrated an inverse correlation between $\mathrm{HbF}$ levels and the frequency of painful crises and early death [50,77]. Moreover, it was shown that the majority of SCA patients from some regions of Saudi Arabia [78] and India [79] who co-inherit another genetic determinant associated with high $\mathrm{HbF}$ levels, have a very mild sickling disorder. These clinical and epidemiological observations are supported by laboratory studies showing that the exclusion of $\mathrm{HbF}$ from the $\mathrm{HbS}$ polymer inhibits $\mathrm{HbS}$ polymerization [80]. The increase of $\mathrm{HbF}$ and F-cells in patients under hydroxyurea treatment results in a decrease of the proportion of dense dehydrated RBCs, an improvement of the mean RBC deformability and a decrease of the robustness of RBC aggregates [81,82], hence decreasing the clinical severity of SCA patients [83]. Note that the impact of hydroxyurea on $\mathrm{HbF}$ and $\mathrm{RBC}$ rheology is not the only factor involved in the improvement of the clinical severity of SCA patients receiving this medication: the pleiotropic effects of hydroxyurea on endothelial activation and adhesion processes, nitric oxide metabolism, oxidative stress, microparticles genesis and thrombosis, also play a role $[84,85]$. While the associations between variable levels of $\mathrm{HbF}$ and disease severity in SCA 
have been widely investigated, the role of $\mathrm{HbF}$, as well as $\mathrm{HbF}$ enhancer such as hydroxyurea, is not well defined in SC disease [85].

\subsection{Oxidative stress}

Oxygen free radicals have been demonstrated to damage RBCs from healthy donors by decreasing their deformability and aggregability, and by increasing the strength of RBC aggregates [86]. RBCs from SCA patients have been reported to generate a 2-fold greater amounts of super-oxide anion $(\mathrm{O} 2 \cdot-)$, hydrogen peroxide $\left(\mathrm{H}_{2} \mathrm{O}_{2}\right)$ and hydroxyl radical $(\bullet \mathrm{OH})$ than healthy RBCs [87-92]. Hierso et al. [93] recently reported higher RBC reactive oxygen species (ROS) content in both SCA and SC patients compared to healthy subjects, with the highest RBC ROS content observed in SCA patients. In parallel, RBC glutathione (GSH) content was lower in sickle cell patients compared to healthy subjects, especially in SCA patients. The increased pro-oxidant generation in SCA patients results in excessive antioxidant consumption and thus decreased antioxidant capacity [94,95]. Hierso et al. [93] recently use t-butyl hydroperoxide (TBHP) as an in-vitro agent to mimic oxidative stress on RBCs from sickle cell patients. The authors showed that TBHP treatment increased RBC ROS production and decreased RBC GSH content in SCA and SC patients, as well as on RBCs from healthy subjects. Concomitantly, TBHP decreased RBC aggregation and increased the strength of $\mathrm{RBC}$ aggregates in these three groups but the increase in RBC aggregates strength was greater in sickle cell patients. TBHP also decreased RBC deformability in the three groups but the impairment was of higher magnitude in sickle cell patients. These data suggest that RBCs from sickle cell patients have an exaggerated response to oxidative stress, which is accompanied by a profound abnormal hemorheological profile, with greater alterations in SCA than in SC patients. Further studies are needed to test the effects of oxidative stress on RBCs from sickle cell patients with or without athalassemia or glucose-6-phosphate deficiency, which are well known to modulate the antioxidant capacity of patients.

\subsection{Nitric oxide (NO)}

Recent evidence supports a key role of the RBC nitric oxide synthase (NOS) activity and RBC NO production in the modulation of RBC deformability of healthy individuals [9698], through S-nitrosylation process of the $\alpha$ - and $\beta$-spectrin chains of the RBC [99]. Grau et al. [99] demonstrated that stimulating the RBC NOS by the PI3 kinase/Akt pathway resulted in a greater amount of $\mathrm{RBC}$ nitrite and an improvement in $\mathrm{RBC}$ deformability in healthy subjects. Grau et al. [100] and Mozar et al. [101] recently focused on the RBC-NOS in SCA and SC patients, respectively: surprisingly, they found higher activity in comparison with healthy individuals, which resulted in a high amount of RBC nitrite and S-nitrosylated aand $\beta$-spectrins. However, in contrast to what happened in healthy RBCs [99], the accumulation of $\mathrm{NO}$ into the RBCs of SCA patients was not associated with an improvement of RBC deformability [100]. It is suspected that the rapid conversion of RBC NO into peroxynitrite would further affect RBC deformability [100].

Several works also investigated the effects of various NO donors, such as sodium nitroprusside (SNP) or deta NONOate, on the RBC deformability of healthy individuals [98]. While some studies showed a positive effect [99,102], others did not report any effect 
[103]. In fact, recent studies found that NO donors protect against the loss of deformability caused by calcium in normal RBCs but no effect of any donors is observed when calcium influx is not induced $[103,104]$. NO is suggested to act as an anti-eryptotic agent (eryptosis $=$ RBC "apoptotic-like" death) [105]. Importantly, the effects of NO donors have been recently tested on sickle RBCs [103]. The authors demonstrated that the addition of SNP (or to a lesser extent, sodium nitrite) on sickle RBCs exposed to deoxygenation to promote dehydration, resulted in substantial improvements in RBC deformability and hydration [103]. SNP had no effect on calcium influx but reduced potassium efflux leading the authors to suggest that SNP and perhaps certain nitrogen oxides (like nitrite) inhibit the Gardos channel and may be able to protect sickle cells from dehydration. These findings are particularly important in the context of complications such as leg ulcers [48] and glomerulopathy [47] where RBC deformability is very reduced. Minitti et al. [106] showed that local application of sodium nitrite $2 \%$ cream on leg ulcers of SCA patients caused a decrease in ulcer size and increased peri-wound cutaneous blood flow. Improved vascular function, as well as hemorheological effects, could be at the origin of these beneficial adaptations.

\section{Conclusion}

Progress has been made in the last decades in the understanding of the pathophysiological mechanisms involved in SCD. Previous and recent studies identified several potential biomarkers and hemorheological predictors of various acute and chronic complications that paved the way for stimulating novel approaches to develop appropriate therapies. Due to its positive effects on various biological parameters, the incorporation of hydroxyurea in the therapeutic arsenal of SCA significantly improved the clinical severity and the quality of life of patients but, can, in some cases, produce medically significant side effects. Several drugs with potential hemorheological impact, such as the Aes-103 molecule (Baxter, USA) which prevents $\mathrm{HbS}$ polymerization and the formation of rigid $\mathrm{RBCs}$ or the poloxamer 188 (Mast Therapeutics, USA) which would decrease RBC aggregability and RBC adhesiveness, are currently tested in the context of SCD. There is no doubt that these recent developments in association with collaborative efforts between scientists from different fields should allow further improvement of the clinical condition of SCD patients.

\section{References}

1. Weatherall DJ. The inherited diseases of hemoglobin are an emerging global health burden. Blood. 2010; 115:4331-6. [PubMed: 20233970]

2. Embury SH. The clinical pathophysiology of sickle cell disease. Annu Rev Med. 1986; 37:361-76. [PubMed: 2423018]

3. Hirsch RE, Raventos-Suarez C, Olson JA, Nagel RL. Ligand state of intraerythrocytic circulating HbC crystals in homozygote CC patients. Blood. 1985; 66:775-7. [PubMed: 2412615]

4. Lin MJ, Nagel RL, Hirsch RE. Acceleration of hemoglobin C crystallization by hemoglobin S. Blood. 1989; 74:1823-5. [PubMed: 2790206]

5. Hannemann A, Weiss E, Rees DC, Dalibalta S, Ellory JC, Gibson JS. The properties of red blood cells from patients heterozygous for $\mathrm{HbS}$ and $\mathrm{HbC}$ (HbSC genotype). Anemia. 2011; 2011:248527. [PubMed: 21490760]

6. Nagel RL, Fabry ME, Steinberg MH. The paradox of hemoglobin SC disease. Blood Rev. 2003; 17:167-78. [PubMed: 12818227] 
7. Lionnet F, Hammoudi N, Stojanovic KS, Avellino V, Grateau G, Girot R, et al. Hemoglobin sickle cell disease complications: a clinical study of 179 cases. Haematologica. 2012; 97:1136-41. [PubMed: 22315500]

8. Chien S, Usami S, Bertles JF. Abnormal rheology of oxygenated blood in sickle cell anemia. J Clin Invest. 1970; 49:623-34. [PubMed: 5443167]

9. Baskurt OK, Meiselman HJ. Blood rheology and hemodynamics. Semin Thromb Hemost. 2003; 29:435-50. [PubMed: 14631543]

10. Vent-Schmidt J, Waltz X, Romana M, Hardy-Dessources MD, Lemonne N, Billaud M, et al. Blood thixotropy in patients with sickle cell anaemia: role of haematocrit and red blood cell rheological properties. PLoS One. 2014; 9:e114412. [PubMed: 25502228]

11. Tsai AG, Acero C, Nance PR, Cabrales P, Frangos JA, Buerk DG, et al. Elevated plasma viscosity in extreme hemodilution increases perivascular nitric oxide concentration and microvascular perfusion. Am J Physiol Heart Circ Physiol. 2005; 288:H1730-9. [PubMed: 15576432]

12. Chien S. Red cell deformability and its relevance to blood flow. Annu Rev Physiol. 1987; 49:17792. [PubMed: 3551796]

13. Baskurt OK, Meiselman HJ. RBC aggregation: more important than RBC adhesion to endothelial cells as a determinant of in vivo blood flow in health and disease. Microcirculation. 2008; 15:58590. [PubMed: 18608991]

14. Rampling MW, Meiselman HJ, Neu B, Baskurt OK. Influence of cell-specific factors on red blood cell aggregation. Biorheology. 2004; 41:91-112. [PubMed: 15090679]

15. Tripette J, Alexy T, Hardy-Dessources MD, Mougenel D, Beltan E, Chalabi T, et al. Red blood cell aggregation, aggregate strength and oxygen transport potential of blood are abnormal in both homozygous sickle cell anemia and sickle-hemoglobin C disease. Haematologica. 2009; 94:10605. [PubMed: 19644138]

16. Alexy T, Pais E, Armstrong JK, Meiselman HJ, Johnson CS, Fisher TC. Rheologic behavior of sickle and normal red blood cell mixtures in sickle plasma: implications for transfusion therapy. Transfusion. 2006; 46:912-8. [PubMed: 16734807]

17. Alexy T, Sangkatumvong S, Connes P, Pais E, Tripette J, Barthelemy JC, et al. Sickle cell disease: selected aspects of pathophysiology. Clin Hemorheol Microcirc. 2010; 44:155-66. [PubMed: 20364061]

18. Waltz X, Hardy-Dessources MD, Lemonne N, Mougenel D, Lalanne-Mistrih ML, Lamarre Y, et al. Is there a relationship between the hematocrit-to-viscosity ratio and microvascular oxygenation in brain and muscle? Clin Hemorheol Microcirc. 2015; 59:37-43. [PubMed: 23719422]

19. Vent-Schmidt J, Waltz X, Pichon A, Hardy-Dessources MD, Romana M, Connes P. Indirect viscosimetric method is less accurate than ektacytometry for the measurement of red blood cell deformability. Clin Hemorheol Microcirc. 2015; 59:115-21. [PubMed: 23594502]

20. Waltz X, Hedreville M, Sinnapah S, Lamarre Y, Soter V, Lemonne N, et al. Delayed beneficial effect of acute exercise on red blood cell aggregate strength in patients with sickle cell anemia. Clin Hemorheol Microcirc. 2012; 52:15-26. [PubMed: 22414551]

21. Connes P, Lamarre Y, Waltz X, Ballas SK, Lemonne N, Etienne-Julan M, et al. Haemolysis and abnormal haemorheology in sickle cell anaemia. Br J Haematol. 2014; 165:564-72. [PubMed: 24611951]

22. Bucherer C, Ladjouzi J, Lacombe C, Lelievre JC, Vandewalle H, Beuzard Y, et al. Effect of deoxygenation on rheological behavior of density separated sickle cell suspensions. Clin Hemorheol. 1992; 12:415-25.

23. Ballas SK, Mohandas N. Sickle red cell microrheology and sickle blood rheology. Microcirculation. 2004; 11:209-25. [PubMed: 15280093]

24. Ballas SK, Smith ED. Red blood cell changes during the evolution of the sickle cell painful crisis. Blood. 1992; 79:2154-63. [PubMed: 1562742]

25. Rieber EE, Veliz G, Pollack S. Red cells in sickle cell crisis: observations on the pathophysiology of crisis. Blood. 1977; 49:967-79. [PubMed: 861378]

26. Kenny MW, Meakin M, Worthington DJ, Stuart J. Erythrocyte deformability in sickle-cell crisis. Br J Haematol. 1981; 49:103-9. [PubMed: 7272221] 
27. Ballas SK. Treatment of pain in adults with sickle cell disease. Am J Hematol. 1990; 34:49-54. [PubMed: 2183594]

28. Clark MR, Mohandas N, Shohet SB. Deformability of oxygenated irreversibly sickled cells. J Clin Invest. 1980; 65:189-96. [PubMed: 7350198]

29. Lawrence C, Fabry ME. Erythrocyte sedimentation rate during steady state and painful crisis in sickle cell anemia. Am J Med. 1986; 81:801-8. [PubMed: 3776987]

30. Awodu OA, Famodu AA, Ajayi OI, Enosolease ME, Olufemi OY, Olayemi E. Using serial haemorheological parameters to assess clinical status in sickle cell anaemia patients in vasoocclussive crisis. Clin Hemorheol Microcirc. 2009; 41:143-8. [PubMed: 19252237]

31. Akinola NO, Stevens SM, Franklin IM, Nash GB, Stuart J. Rheological changes in the prodromal and established phases of sickle cell vaso-occlusive crisis. Br J Haematol. 1992; 81:598-602. [PubMed: 1390248]

32. Richardson SG, Matthews KB, Stuart J, Geddes AM, Wilcox RM. Serial changes in coagulation and viscosity during sickle-cell crisis. Br J Haematol. 1979; 41:95-103. [PubMed: 420740]

33. Gladwin MT, Vichinsky E. Pulmonary complications of sickle cell disease. N Engl J Med. 2008; 359:2254-65. [PubMed: 19020327]

34. Kato GJ, Gladwin MT, Steinberg MH. Deconstructing sickle cell disease: reappraisal of the role of hemolysis in the development of clinical subphenotypes. Blood Rev. 2007; 21:37-47. [PubMed: 17084951]

35. Connes P, Verlhac S, Bernaudin F. Advances in understanding the pathogenesis of cerebrovascular vasculopathy in sickle cell anaemia. Br J Haematol. 2013; 161:484-98. [PubMed: 23496688]

36. Camus SM, Gausseres B, Bonnin P, Loufrani L, Grimaud L, Charue D, et al. Erythrocyte microparticles can induce kidney vaso-occlusions in a murine model of sickle cell disease. Blood. 2012; 120:5050-8. [PubMed: 22976952]

37. Liu C, Zhao W, Christ GJ, Gladwin MT, Kim-Shapiro DB. Nitric oxide scavenging by red cell microparticles. Free Radic Biol Med. 2013; 65:1164-73. [PubMed: 24051181]

38. Kato GJ, Martyr S, Blackwelder WC, Nichols JS, Coles WA, Hunter LA, et al. Levels of soluble endothelium-derived adhesion molecules in patients with sickle cell disease are associated with pulmonary hypertension, organ dysfunction, and mortality. Br J Haematol. 2005; 130:943-53. [PubMed: 16156864]

39. Lin EE, Rodgers GP, Gladwin MT. Hemolytic anemia-associated pulmonary hypertension in sickle cell disease. Curr Hematol Rep. 2005; 4:117-25. [PubMed: 15720960]

40. Reiter CD, Wang X, Tanus-Santos JE, Hogg N, Cannon RO 3rd, Schechter AN, et al. Cell-free hemoglobin limits nitric oxide bioavailability in sickle-cell disease. Nat Med. 2002; 8:1383-9. [PubMed: 12426562]

41. Bunn HF, Nathan DG, Dover GJ, Hebbel RP, Platt OS, Rosse WF, et al. Pulmonary hypertension and nitric oxide depletion in sickle cell disease. Blood. 2010; 116:687-92. [PubMed: 20395414]

42. Gladwin MT, Sachdev V, Jison ML, Shizukuda Y, Plehn JF, Minter K, et al. Pulmonary hypertension as a risk factor for death in patients with sickle cell disease. N Engl J Med. 2004; 350:886-95. [PubMed: 14985486]

43. Nebor D, Broquere C, Brudey K, Mougenel D, Tarer V, Connes P, et al. Alpha-thalassemia is associated with a decreased occurrence and a delayed age-at-onset of albuminuria in sickle cell anemia patients. Blood Cells Mol Dis. 2010; 45:154-8. [PubMed: 20598923]

44. Bowers AS, Reid HL, Greenidge A, Landis C, Reid M. Blood viscosity and the expression of inflammatory and adhesion markers in homozygous sickle cell disease subjects with chronic leg ulcers. PLoS One. 2013; 8:e68929. [PubMed: 23922670]

45. Bernaudin F, Verlhac S, Chevret S, Torres M, Coic L, Arnaud C, et al. G6PD deficiency, absence of alpha-thalassemia, and hemolytic rate at baseline are significant independent risk factors for abnormally high cerebral velocities in patients with sickle cell anemia. Blood. 2008; 112:4314-7. [PubMed: 18772456]

46. DeBaun MR, Sarnaik SA, Rodeghier MJ, Minniti CP, Howard TH, Iyer RV, et al. Associated risk factors for silent cerebral infarcts in sickle cell anemia: low baseline hemoglobin, sex, and relative high systolic blood pressure. Blood. 2012; 119:3684-90. [PubMed: 22096242] 
47. Lamarre Y, Romana M, Lemonne N, Hardy-Dessources MD, Tarer V, Mougenel D, et al. Alpha thalassemia protects sickle cell anemia patients from macro-albuminuria through its effects on red blood cell rheological properties. Clin Hemorheol Microcirc. 2014; 57:63-72. [PubMed: 24004554]

48. Connes P, Lamarre Y, Hardy-Dessources MD, Lemonne N, Waltz X, Mougenel D, et al. Decreased hematocrit-to-viscosity ratio and increased lactate dehydrogenase level in patients with sickle cell anemia and recurrent leg ulcers. PLoS One. 2013; 8:e79680. [PubMed: 24223994]

49. Bartolucci P, Brugnara C, Teixeira-Pinto A, Pissard S, Moradkhani K, Jouault H, et al. Erythrocyte density in sickle cell syndromes is associated with specific clinical manifestations and hemolysis. Blood. 2012; 120:3136-41. [PubMed: 22919030]

50. Platt OS, Thorington BD, Brambilla DJ, Milner PF, Rosse WF, Vichinsky E, et al. Pain in sickle cell disease. Rates and risk factors. N Engl J Med. 1991; 325:11-6. [PubMed: 1710777]

51. Castro O, Brambilla DJ, Thorington B, Reindorf CA, Scott RB, Gillette P, et al. The acute chest syndrome in sickle cell disease: incidence and risk factors. The cooperative study of sickle cell disease. Blood. 1994; 84:643-9. [PubMed: 7517723]

52. Lande WM, Andrews DL, Clark MR, Braham NV, Black DM, Embury SH, et al. The incidence of painful crisis in homozygous sickle cell disease: correlation with red cell deformability. Blood. 1988; 72:2056-9. [PubMed: 3196878]

53. Nebor D, Bowers A, Hardy-Dessources MD, Knight-Madden J, Romana M, Reid H, et al. Frequency of pain crises in sickle cell anemia and its relationship with the sympathovagal balance, blood viscosity and inflammation. Haematologica. 2011; 96:1589-94. [PubMed: 21750084]

54. Lamarre Y, Romana M, Waltz X, Lalanne-Mistrih ML, Tressieres B, Divialle-Doumdo L, et al. Hemorheological risk factors of acute chest syndrome and painful vaso-occlusive crisis in children with sickle cell disease. Haematologica. 2012; 97:1641-7. [PubMed: 22689686]

55. Lamarre Y, Hardy-Dessources MD, Romana M, Lalanne-Mistrih ML, Waltz X, Petras M, et al. Relationships between systemic vascular resistance, blood rheology and nitric oxide in children with sickle cell anemia or sickle cell-hemoglobin C disease. Clin Hemorheol Microcirc. 2014; 58:307-16. [PubMed: 23302597]

56. Mohan JS, Lip GY, Blann AD, Bareford D, Marshall JM. Endothelium-dependent and endothelium-independent vasodilatation of the cutaneous circulation in sickle cell disease. Eur J Clin Invest. 2011; 41:546-51. [PubMed: 21158851]

57. Lemaire C, Lamarre Y, Lemonne N, Waltz X, Chahed S, Cabot F, et al. Severe proliferative retinopathy is associated with blood hyperviscosity in sickle cell hemoglobin-C disease but not in sickle cell anemia. Clin Hemorheol Microcirc. 2013; 55:205-12. [PubMed: 23076002]

58. Lemonne N, Lamarre Y, Romana M, Hardy-Dessources MD, Lionnet F, Waltz X, et al. Impaired blood rheology plays a role in the chronic disorders associated with sickle cell-hemoglobin C disease. Haematologica. 2014; 99:74-5. [PubMed: 24633868]

59. Rosse WF, Narla M, Petz LD, Steinberg MH. New views of sickle cell disease pathophysiology and treatment. Hematology Am Soc Hematol Educ Program. 2000:2-17. [PubMed: 11701532]

60. Lemonne N, Lamarre Y, Romana M, Mukisi-Mukaza M, Hardy-Dessources MD, Tarer V, et al. Does increased red blood cell deformability raise the risk for osteonecrosis in sickle cell anemia? Blood. 2013; 121:3054-6. [PubMed: 23580637]

61. Milner PF, Kraus AP, Sebes JI, Sleeper LA, Dukes KA, Embury SH, et al. Sickle cell disease as a cause of osteonecrosis of the femoral head. N Engl J Med. 1991; 325:1476-81. [PubMed: 1944426]

62. Ballas SK. Sickle cell anemia with few painful crises is characterized by decreased red cell deformability and increased number of dense cells. Am J Hematol. 1991; 36:122-30. [PubMed: 1707225]

63. Ballas SK, Larner J, Smith ED, Surrey S, Schwartz E, Rappaport EF. Rheologic predictors of the severity of the painful sickle cell crisis. Blood. 1988; 72:1216-23. [PubMed: 3167204]

64. Kaul DK, Fabry ME. In vivo studies of sickle red blood cells. Microcirculation. 2004; 11:153-65. [PubMed: 15280089] 
65. Mohandas N, Evans E. Rheological and adherence properties of sickle cells. Potential contribution to hematologic manifestations of the disease. Ann N Y Acad Sci. 1989; 565:327-37. [PubMed: 2672968]

66. Steinberg MH. Predicting clinical severity in sickle cell anaemia. Br J Haematol. 2005; 129:46581. [PubMed: 15877729]

67. Guasch A, Zayas CF, Eckman JR, Muralidharan K, Zhang W, Elsas LJ. Evidence that microdeletions in the alpha globin gene protect against the development of sickle cell glomerulopathy in humans. J Am Soc Nephrol. 1999; 10:1014-9. [PubMed: 10232687]

68. Joly, P; Garnier, N; Kebaili, K; Griffon-Renoux, C; Dony, A; Cheikh, N; , et al. G6PD deficiency and absence of $a$-thalassaemia increase the risk for cerebral vasculopathy in children with sickle cell anaemia. Eur J Haematol. Jun 13, 2015

69. Higgs DR, Aldridge BE, Lamb J, Clegg JB, Weatherall DJ, Hayes RJ, et al. The interaction of alpha-thalassemia and homozygous sickle-cell disease. N Engl J Med. 1982; 306:1441-6. [PubMed: 6176865]

70. Koshy M, Entsuah R, Koranda A, Kraus AP, Johnson R, Bellvue R, et al. Leg ulcers in patients with sickle cell disease. Blood. 1989; 74:1403-8. [PubMed: 2475188]

71. Nolan VG, Wyszynski DF, Farrer LA, Steinberg MH. Hemolysis-associated priapism in sickle cell disease. Blood. 2005; 106:3264-7. [PubMed: 15985542]

72. Embury SH, Clark MR, Monroy G, Mohandas N. Concurrent sickle cell anemia and alphathalassemia. Effect on pathological properties of sickle erythrocytes. J Clin Invest. 1984; 73:11623. [PubMed: 6690472]

73. Steinberg MH, Rosenstock W, Coleman MB, Adams JG, Platica O, Cedeno M, et al. Effects of thalassemia and microcytosis on the hematologic and vasoocclusive severity of sickle cell anemia. Blood. 1984; 63:1353-60. [PubMed: 6722353]

74. Ballas SK, Talacki CA, Rao VM, Steiner RM. The prevalence of avascular necrosis in sickle cell anemia: correlation with alpha-thalassemia. Hemoglobin. 1989; 13:649-55. [PubMed: 2634666]

75. Nagel RL, Labie D. The consequences and implications of the multicentric origin of the $\mathrm{Hb} \mathrm{S}$ gene. Prog Clin Biol Res. 1985; 191:93-103. [PubMed: 2413486]

76. Powars DR, Meiselman HJ, Fisher TC, Hiti A, Johnson C. Beta-S gene cluster haplotypes modulate hematologic and hemorheologic expression in sickle cell anemia. Use in predicting clinical severity. Am J Pediatr Hematol Oncol. 1994; 16:55-61. [PubMed: 7508688]

77. Platt OS, Brambilla DJ, Rosse WF, Milner PF, Castro O, Steinberg MH, et al. Mortality in sickle cell disease. Life expectancy and risk factors for early death. N Engl J Med. 1994; 330:1639-44. [PubMed: 7993409]

78. Perrine RP, Pembrey ME, John P, Perrine S, Shoup F. Natural history of sickle cell anemia in saudi arabs. A study of 270 subjects. Ann Intern Med. 1978; 88:1-6. [PubMed: 619731]

79. Brittenham G, Lozoff B, Harris JW, Mayson SM, Miller A, Huisman TH. Sickle cell anemia and trait in southern India: further studies. Am J Hematol. 1979; 6:107-23. [PubMed: 474571]

80. Poillon WN, Kim BC, Rodgers GP, Noguchi CT, Schechter AN. Sparing effect of hemoglobin F and hemoglobin A2 on the polymerization of hemoglobin $S$ at physiologic ligand saturations. Proc Natl Acad Sci U S A. 1993; 90:5039-43. [PubMed: 7685112]

81. Lemonne N, Charlot K, Waltz X, Ballas SK, Lamarre Y, Lee K, et al. Hydroxyurea treatment does not increase blood viscosity and improves red blood cell rheology in sickle cell anemia. Haematologica. Jul 2.2015

82. Ballas SK, Dover GJ, Charache S. Effect of hydroxyurea on the rheological properties of sickle erythrocytes in vivo. Am J Hematol. 1989; 32:104-11. [PubMed: 2757007]

83. Charache S, Terrin ML, Moore RD, Dover GJ, Barton FB, Eckert SV, et al. Effect of hydroxyurea on the frequency of painful crises in sickle cell anemia. Investigators of the multicenter study of hydroxyurea in sickle cell anemia. N Engl J Med. 1995; 332:1317-22. [PubMed: 7715639]

84. Green NS, Barral S. Emerging science of hydroxyurea therapy for pediatric sickle cell disease. Pediatr Res. 2014; 75:196-204. [PubMed: 24252885]

85. Ware RE. How I use hydroxyurea to treat young patients with sickle cell anemia. Blood. 2010; 115:5300-11. [PubMed: 20223921] 
86. Baskurt OK, Temiz A, Meiselman HJ. Effect of superoxide anions on red blood cell rheologic properties. Free Radic Biol Med. 1998; 24:102-10. [PubMed: 9436619]

87. Akohoue SA, Shankar S, Milne GL, Morrow J, Chen KY, Ajayi WU, et al. Energy expenditure, inflammation, and oxidative stress in steady-state adolescents with sickle cell anemia. Pediatr Res. 2007; 61:233-8. [PubMed: 17237728]

88. Aslan M, Thornley-Brown D, Freeman BA. Reactive species in sickle cell disease. Ann N Y Acad Sci. 2000; 899:375-91. [PubMed: 10863554]

89. Hebbel RP, Morgan WT, Eaton JW, Hedlund BE. Accelerated autoxidation and heme loss due to instability of sickle hemoglobin. Proc Natl Acad Sci U S A. 1988; 85:237-41. [PubMed: 3422420]

90. Klings ES, Farber HW. Role of free radicals in the pathogenesis of acute chest syndrome in sickle cell disease. Respir Res. 2001; 2:280-5. [PubMed: 11686897]

91. Rice-Evans C, Omorphos SC, Baysal E. Sickle cell membranes and oxidative damage. Biochem J. 1986; 237:265-9. [PubMed: 3800879]

92. Sheng K, Shariff M, Hebbel RP. Comparative oxidation of hemoglobins a and S. Blood. 1998; 91:3467-70. [PubMed: 9558406]

93. Hierso R, Waltz X, Mora P, Romana M, Lemonne N, Connes P, et al. Effects of oxidative stress on red blood cell rheology in sickle cell patients. Br J Haematol. 2014; 166:601-6. [PubMed: 24754710]

94. Banerjee T, Kuypers FA. Reactive oxygen species and phosphatidylserine externalization in murine sickle red cells. Br J Haematol. 2004; 124:391-402. [PubMed: 14717789]

95. Chaves MA, Leonart MS, do Nascimento AJ. Oxidative process in erythrocytes of individuals with hemoglobin S. Hematology. 2008; 13:187-92. [PubMed: 18702879]

96. Grau, M; Friederichs, P; Krehan, S; Koliamitra, C; Suhr, F; Bloch, W. Decrease in red blood cell deformability is associated with a reduction in RBC-NOS activation during storage. Clin Hemorheol Microcirc. Jun 13, 2014

97. Kleinbongard P, Schulz R, Rassaf T, Lauer T, Dejam A, Jax T, et al. Red blood cells express a functional endothelial nitric oxide synthase. Blood. 2006; 107:2943-51. [PubMed: 16368881]

98. Simmonds MJ, Detterich JA, Connes P. Nitric oxide, vasodilation and the red blood cell. Biorheology. 2014; 51:121-34. [PubMed: 24819865]

99. Grau M, Pauly S, Ali J, Walpurgis K, Thevis M, Bloch W, et al. RBC-NOS-dependent Snitrosylation of cytoskeletal proteins improves RBC deformability. PLoS One. 2013; 8:e56759. [PubMed: 23424675]

100. Grau M, Mozar A, Charlot K, Lamarre Y, Weyel L, Suhr F, et al. High red blood cell nitric oxide synthase activation is not associated with improved vascular function and red blood cell deformability in sickle cell anaemia. Br J Haematol. 2015; 168:728-36. [PubMed: 25316332]

101. Mozar A, Grau M, Lamarre Y, Weyel L, Suhr F, Collins B, et al. Red blood cell nitric oxide synthase activation is increased in patients with sickle cell hemoglobin $\mathrm{C}$ disease. Am J Hematol. 2015; 90:E30-2. [PubMed: 25379969]

102. Bor-Kucukatay M, Wenby RB, Meiselman HJ, Baskurt OK. Effects of nitric oxide on red blood cell deformability. Am J Physiol Heart Circ Physiol. 2003; 284:H1577-84. [PubMed: 12521942]

103. Belanger, AM; Keqqi, C; Kanias, T; Gladwin, MT; Kim-Shapiro, DB. Effects of nitric oxide and its congeners on sickle red blood cell deformability. Transfusion. Apr 23, 2015

104. Barodka V, Mohanty JG, Mustafa AK, Santhanam L, Nyhan A, Bhunia AK, et al. Nitro-prusside inhibits calcium-induced impairment of red blood cell deformability. Transfusion. 2014; 54:434 44. [PubMed: 23781865]

105. Bogdanova A, Makhro A, Wang J, Lipp P, Kaestner L. Calcium in red blood cells-a perilous balance. Int J Mol Sci. 2013; 14:9848-72. [PubMed: 23698771]

106. Minniti CP, Gorbach AM, Xu D, Yi Hon Y, Delaney KM, Seidel M, et al. Topical sodium nitrite for chronic leg ulcers in patients with sickle cell anaemia: a phase 1 dose-finding safety and tolerability trial. Lancet Haematol. 2014; 1:e95-103. [PubMed: 25938131]

107. Nagaoka T, Yoshida A. Noninvasive evaluation of wall shear stress on retinal micro-circulation in humans. Invest Ophthalmol Vis Sci. 2006; 47:1113-9. [PubMed: 16505049] 
108. Nicolete R, Rius C, Piqueras L, Jose PJ, Sorgi CA, Soares EG, et al. Leukotriene B4-loaded microspheres: a new therapeutic strategy to modulate cell activation. BMC Immunol. 2008; 9:36. [PubMed: 18627613]

109. Papaioannou TG, Stefanadis C. Vascular wall shear stress: basic principles and methods. Hellenic J Cardiol. 2005; 46:9-15. [PubMed: 15807389]

110. Stoltz JF. Hemorheology: pathophysiological significance. Acta Med Port. 1985; 6:S4-13. [PubMed: 3914190]

111. Wray DW, Uberoi A, Lawrenson L, Richardson RS. Heterogeneous limb vascular responsiveness to shear stimuli during dynamic exercise in humans. J Appl Physiol. 2005; 99:81-6. [PubMed: 15718401] 


\section{Practice points}

- $\quad$ The study of blood rheology in patients with SCD might allow for the identification of biomarkers of acute VOC.

- Study of blood rheological parameters and genetic/epigenetic factors may help in identifying sickle cell subgroups at risk for specific acute and chronic complications. 


\section{Research agenda}

- Development of efficient strategies and therapies to improve the hemorheological abnormalities and clinical condition of patients with $\mathrm{Hb} \mathrm{SC}$ disease.

- Identification of biomarkers predicting adverse clinical events in SC disease.

- Development of efficient hemorheological therapies to prevent and improve the clinical management of vaso-occlusive complications in sickle cell disease. 


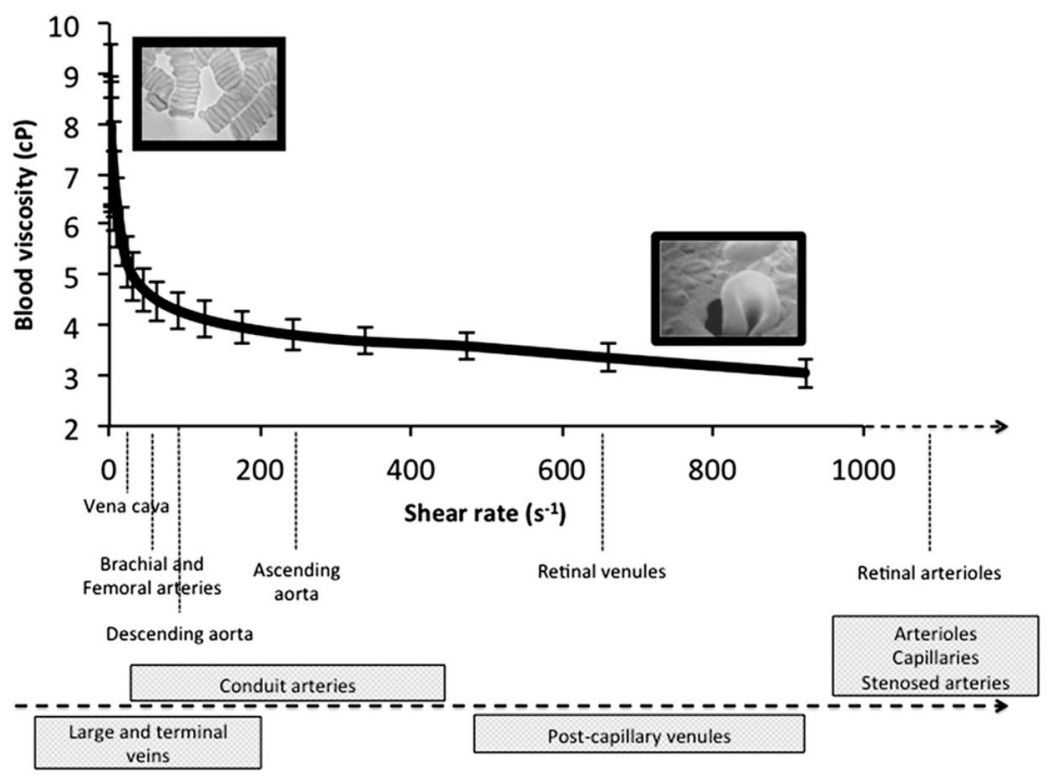

Fig. 1.

Effects of shear rate and red blood cell rheological properties on blood viscosity. This figure shows the shear-thinning properties of blood, with blood viscosity decreasing when shear rate increases. At low shear rates, blood viscosity mainly depends on red blood cell aggregation. As the shear rate increases, red blood cell aggregates progressively dissociate. At high shear rate, the ability of red blood cell to deform under shear affects blood viscosity. The figure also gives information about the shear rate values that can be found in the vascular system [107-111]. In a given vessel, shear rate can be estimated by $8 *$ mean centerline blood velocity / diameter of the vessel. Photography (courtesy of Dr. Max R Hardeman): on the left = red blood cell aggregates; on the right: red blood cell in the process of deforming to pass through a micropore of $5 \mu \mathrm{m}$. 


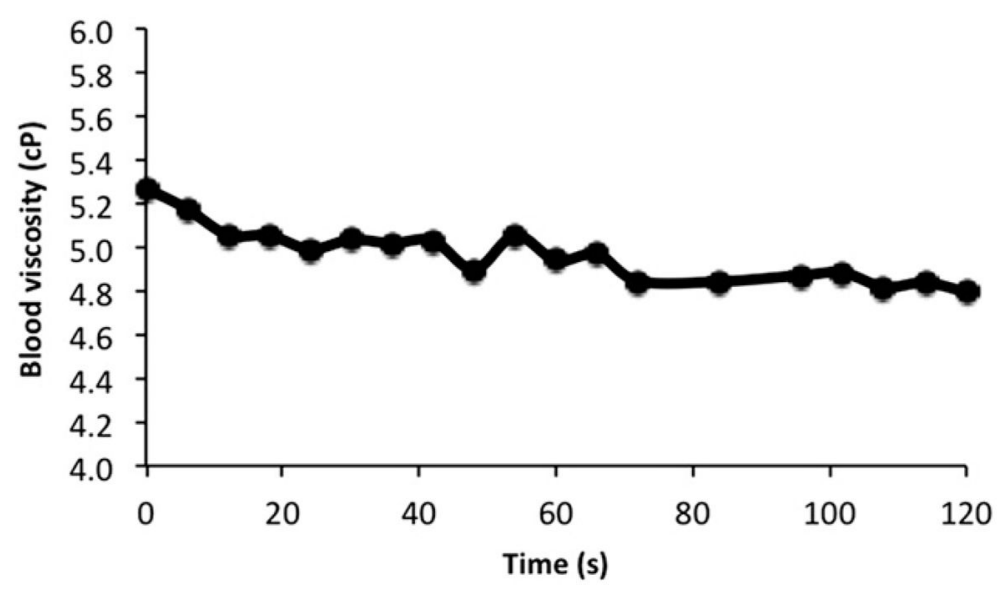

Fig. 2.

Effects of time exposure at a fixed shear rate on blood viscosity. This figure shows the decrease over time ( $2 \mathrm{~min}$ ) of blood viscosity when the fluid is sheared at $10 \mathrm{~s}^{-1}$, which reflects the thixotropic property of blood. The progressive rupture of red blood cell aggregates over time makes the blood less viscous. 

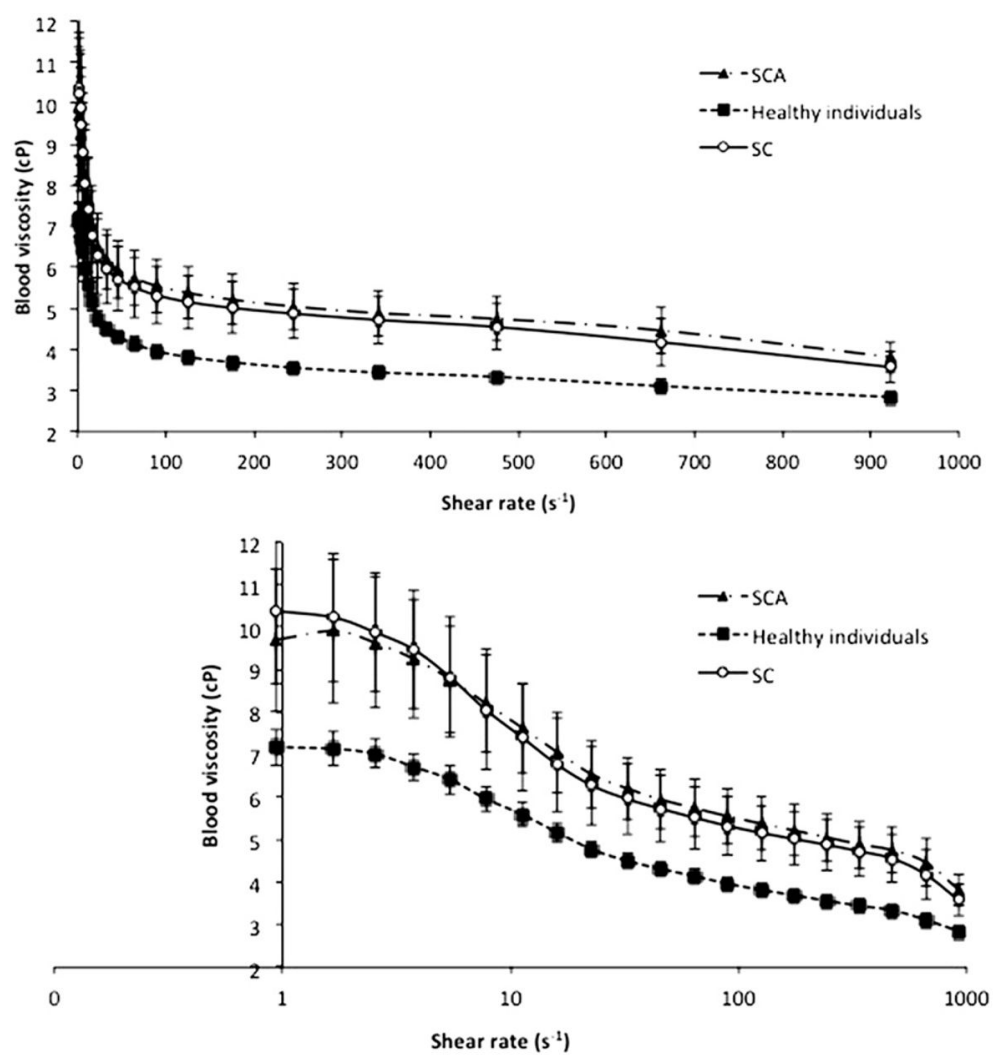

Fig. 3.

Blood viscosity vs shear rate curves in healthy individuals, SC and SCA patients at adjusted hematocrit (40\%). The second graphic (at the bottom) shows the same data than the first one (at the top) but shear rate values are log transformed to better see the difference at low shear rates. The two sickle cell groups exhibit higher blood viscosity at $40 \%$ hematocrit than the healthy population because of the presence of robust red blood cell aggregates and rigid red blood cells. 